for 95.5 per cent of the total units generated. The effect of the progressive improvements in steam power station practice which have taken place in the stations of authorised undertakers during the past four years alone is shown by the fact that the average number of electric units generated per ton of coal and coke consumed has risen from 1,200 in 1930 to 1,425 in 1934, an increase of more than 18 per cent. The Commissioners deprecate the custom of some public supply authorities, when advertising for tenders, of specifying that the particular plant or materials should be the product of a particular firm or group of manufacturers.

\section{Thermal-Electric Stations}

A strong case is made, in a paper read before the Institution of Civil Engineers on December 10 by Mr. S. B. Donkin, for the adoption, where possible, of the thermal-electric power station. The ordinary electric power station, using coal as a source of energy, has an overall thermal efficiency of about thirty per cent, whereas in a thermal-electric station which, besides supplying electric energy, also distributes the latent heat of the steam for domestic, horticultural and industrial heating, an overall efficiency of 60-70 per cent can be obtained. Where this system could be successfully adopted, it would solve the difficulty which is likely to arise if coal prices advance. That it is practicable is shown by the stations established in the United States, in the U.S.S.R. and elsewhere. Industrial plants operating on this system have been installed in England, but these are necessarily limited in effect to the requirements of the individual factory.

ThE success of a public station would depend upon maintaining a balance between the electricity demand and the heat demand, for the waste heat available rises and falls with the rate of electricity generation; as a general rule, the heat requirements would be greatest in the early part of the day, while the electricity peak occurs in the late aftermoon; seasonal variations are much more marked. A solution might be found in the inter-connexion of the electric side with that of the authorised electrical undertaking in the district. It is admitted that such stations could not easily be established in our older manufacturing towns owing to the cost of installing the heatdistribution network in congested streets already provided with electricity, gas, water, sewerage and drainage services. Mr. Donkin claims, however, that in laying out new industrial areas it would be possible to arrange for the supply of heat and electricity from a combined thermal-electric station, high-grade heat being supplied for manufacturing purposes, medium for domestic uses and low-grade for horticultural needs. To attain the high thermal efficiency quoted, it is necessary to use boilers operating at pressures of 2,000 lb. per square inch or more. The paper includes the diagrammatic lay-out of an ideal industrial town planned on these lines, and reference is made to existing stations.

\section{New Australia-Tasmania Submarine Cable}

The new submarine cable which was successfully laid across the Bass Strait last November marks a notable advance in the technique of submarine cable transmission. Before laying this cable, the Australian Government made a searching inquiry into the relative merits of radio and cable systems of communication, and came to the conclusion that for the objects in view the cable system was the more desirable as it is more trustworthy and easier to make the messages secret. In the Engineering Supplement to the Siemens Magazine of January, a technical description is given of this new cable. It links the telephone and telegraph service of the mainland of Australia with Tasmania. Its length of 161 nautical miles is divided into two sections. The northern section, 79 miles in length, joins King Island to Apollo Bay, Victoria, and then by overhead lines and underground cables joins the trunk exchange at Melbourne. The southern section from King Island goes to the northern coast of Tasmania and then by land line to the Launceston exchange. Inter-connexion is thus effected with the existing network of communications in Australia and Tasmania. This cable, although it has only one insulated conductor, allows no less than five telephone and seven high-speed telegraph channels to be operated simultaneously. In addition, it provides for the transmission of a broadcast programme. Subscribers in Tasmania can now communicate directly with Great Britain by telephone. The adoption of a high-frequency carrier system was influenced by the fact that it is easy to repair. Cable ships are not always available for immediate service in Australian waters and this type of cable is the easiest to repair. There are already two carrier frequency submarine cables in operation. One connects Teneriffe with Gran Canaria, a distance of forty miles, and the other Key-West to Havana, a distance of 109 miles. Both these cables operate only three telephone circuits.

\section{Bats in Belfries and Elsewhere}

THE problem of eliminating bats from churchsteeples has puzzled many a churchwarden, and was responsible for the introduction to England of that unwelcome guest, the little owl. Solutions to that, and to the general problem of the roosting of bats in homes and occupied buildings, are offered by the United States Bureau of Biological Survey, in Leaflet 109 (Sept. 1935). The objection to the presence of bats is partly due to an aversion which many people feel towards them, but more substantially to the highly objectionable stench of the droppings and urine which collect where bats are roosting in numbers. There are two main lines of procedure in breaking up a bat-roost. The most satisfactory and the only permanent way is to make the building bat-proof by closing all entrances by strips of metal or wood or plugging them with rags (of course after the bats have left their roost in the evening). A good com. position for larger openings is tarred hemp fibre such as is used for calking ships. The second method is sometimes simpler-the use of a repellant such as 